\title{
Relationship Quality Between In-Groups And Out-Groups
}

Prem Shamdasani, National University of Singapore, Singapore Kwon Jung, KDI School of Public Policy, Korea

\begin{abstract}
This study aims to investigate the differences in relationship quality between in-group and out-group relational ties between providers and customers of personal life insurance service. Based on the model proposed by Crosby, Evans, and Cowles (1990), the relationship quality model used in this study is modified to be better fitted to the personal life insurance service context by incorporating communication behaviors as antecedent variables of relationship quality.
\end{abstract}

The proposed model was tested with 286 life insurance customers. The results found different patterns of relationships between the in-group and the out-group relational ties between a salesperson and a customer. The results also found significant influence of communication behaviors on relationship quality together with other antecedent variables.

Keywords: relationship quality; in-group and out-group relational ties; unsought services

\section{INTRODUCTION}

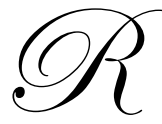

elationship marketing has been one of the most frequently used marketing buzzwords since the early 1990s. Today, most companies are implementing some form of relationship marketing activities as their key marketing strategy to gain success in the competitive market environment (Day, 2000; Gordon, McKeage, and Fox, 1998). The key concept in relationship marketing is building long-term relationships with customers. Zeithaml, Bitner, and Gremler (2008) have identified "relationship marketing" as a philosophy of doing business, a strategic orientation that focuses on keeping and improving relationship with current customers, rather than on acquiring new customers. Morgan and Hunt (1994) explain it as all marketing activities directed toward establishing, developing, and maintaining successful relational exchanges with customers. Relationships with customers have become particularly important in the service industry because of a unique linkage between service and relationship. Services, such as banking, medical and insurance, are highly involved and characterized by variability and complexity in their service contents and qualities. These characteristics make many customers seek long-term relationships with service providers (Berry, 1995).

Since the first mention of the relationship marketing concept by Berry (1983), there has been a growing body of literature that brings forth the relationship marketing paradigm. One of the main focuses of the literature has been on identifying key relational constructs. Relationship quality, a concept presented to marketing practitioners and researchers in the context of the Ericsson Quality program in 1985 by Gümmerson (1987), has been one of the key concepts in the relationship marketing paradigm over the last two decades (Athanasopoulou, 2009; HennigThurau, Gwinner, and Gremler, 2002; Palmatier et al., 2006; Vieira, Winklhofer, and Ennew, 2008). Past literature on relationship quality has focused on identifying key dimensions, antecedents, and consequences of relationship quality and on examining mediating effects of relationship quality between the antecedents and the consequences. Although most studies are empirically rigorous, there has been no consensus on the framework so far (Athanasopoulou, 2009). Rather, the existing literature offers a wide range of variables, especially for the antecedents of relationship quality.

One reason for the high degree of ambiguity about the nature and determinants of relationship quality may have to do with the context dependent nature of the relationship quality construct (Vieira, Winklhofer, and Ennew, 
2008). Relationship is basically context dependent. Thus, depending on different industries, a different set of factors may be influential in the relationship. While it is important to find out a more generalizable framework across industries, it is equally important and necessary to identify an industry-specific set of factors in explaining the phenomenon. The first objective of this study is to identify and test a relevant set of factors of relationship quality phenomenon in the personal life insurance industry. Compared to other services, personal life insurance service is an example of unsought services where the consumer knows about but does not normally think of buying (Kotler and Amstrong, 2010). By their very nature, we expect that unsought services need somewhat different approaches in their relational marketing efforts.

Relationship quality phenomenon may also be different according to varying degrees of relationships between buyers and sellers. It is possible that the mechanism behind relationship quality may be different according to different stages of relationship development or different groups of people with different relational backgrounds. To the best of our knowledge, no attempt has been made so far to examine a possible moderating effect of different relationship backgrounds between salesperson and customer in the context of relationship quality phenomenon. In selling unsought services, salespeople naturally target people who are close to them as well as general people whom they don't know well. This study aims to examine differences in relationship quality patterns between groups of people with varying degrees of relational background. More specifically, it compares in-group and out-group relationship between salesperson and customer and examines whether the relational difference makes differential effects on antecedents and consequences of relationship quality between personal life insurance agents and their customers.

The in-group and out-group difference is examined in a Chinese setting because the Chinese society is relationship-oriented (Yau et al., 2000). The Chinese make a clear distinction between insiders ('zijiren') and outsiders ('wairen'). This distinction exists on all levels of interpersonal interactions and provides specific rules of interaction in Chinese interpersonal relationships. Insiders are treated differently from outsiders and a fellow insider often enjoys privileges and treatment beyond an outsider's comprehension (Gao, 1996). The tendency to treat people differentially based on one's relationship with them is the reason why 'guanxi' is of such importance in Chinese culture (Farh et al., 1998). The notion of the in-group is important in other collectivist cultures as well. Members of other collectivist cultures also make clear distinctions between in-groups and out-groups and apply different standards to in-groups (Hofstede, 1980; Triandis, 1988). To date, however, only a limited number of empirical studies of relationship quality have been conducted in East Asian countries (Chen, Shi and Dong, 2007). The findings of this study hopefully fill the gaps in the research and to provide useful recommendations for the most suitable relational marketing approaches to salespeople when they are dealing with people of different degree of relational background in the unsought service context.

\section{CONCEPTUAL BACKGROUND}

The relationship quality model used in this study is a modification and extension of the relationship quality model proposed by Crosby, Evans, and Cowles (1990). The model predicts that the various antecedents have a bearing on relationship quality, which in turn influences customer loyalty. Past studies on relationship quality have identified such constructs as customer satisfaction and mutual trust as key dimensions of relationship quality (Anderson and Gerbing, 1988; Crosby et al., 1990; Perrien and Ricard, 1995; Wray, Palmer, and Bejou, 1994). The existing literature, however, offers a wide range of antecedents for relationship quality. Among them, salesperson attributes and relational selling behaviors are most commonly used factors. Recently, however, a focus has been placed on the communication aspect of relationships (Boorom, Goolsby, and Ramsey, 1998; Duncan and Moriarty, 1998; Friman et al., 2002; Morgan and Hunt, 1994; Ramsey and Sohi, 1997; Sanzo et al., 2003; Selnes, 1998; Smith, 1998). Relationships between the salesperson and the customer could be built through communication between them. According to Duncan and Moriarty (1998), relationship-marketing literature has neglected to include the communication process as a critical dimension in the building of relationships. In life insurance industry context, communication is one of the vital factors in building and maintaining relationships. Based on the relationship quality model of Crosby et al. (1990), this study propose a more relevant framework of relationship quality for the life insurance industry by additionally considering communication behaviors of the salesperson, which includes salesperson's communication style and listening behaviors, as additional antecedents of relationship quality. Figure 1 summarizes the model. 
In-group and out-group relational ties are hypothesized to act as moderating variables affecting the relationship among the factors. The various hypothesized constructs and the proposed relationships between the constructs are discussed in the following.

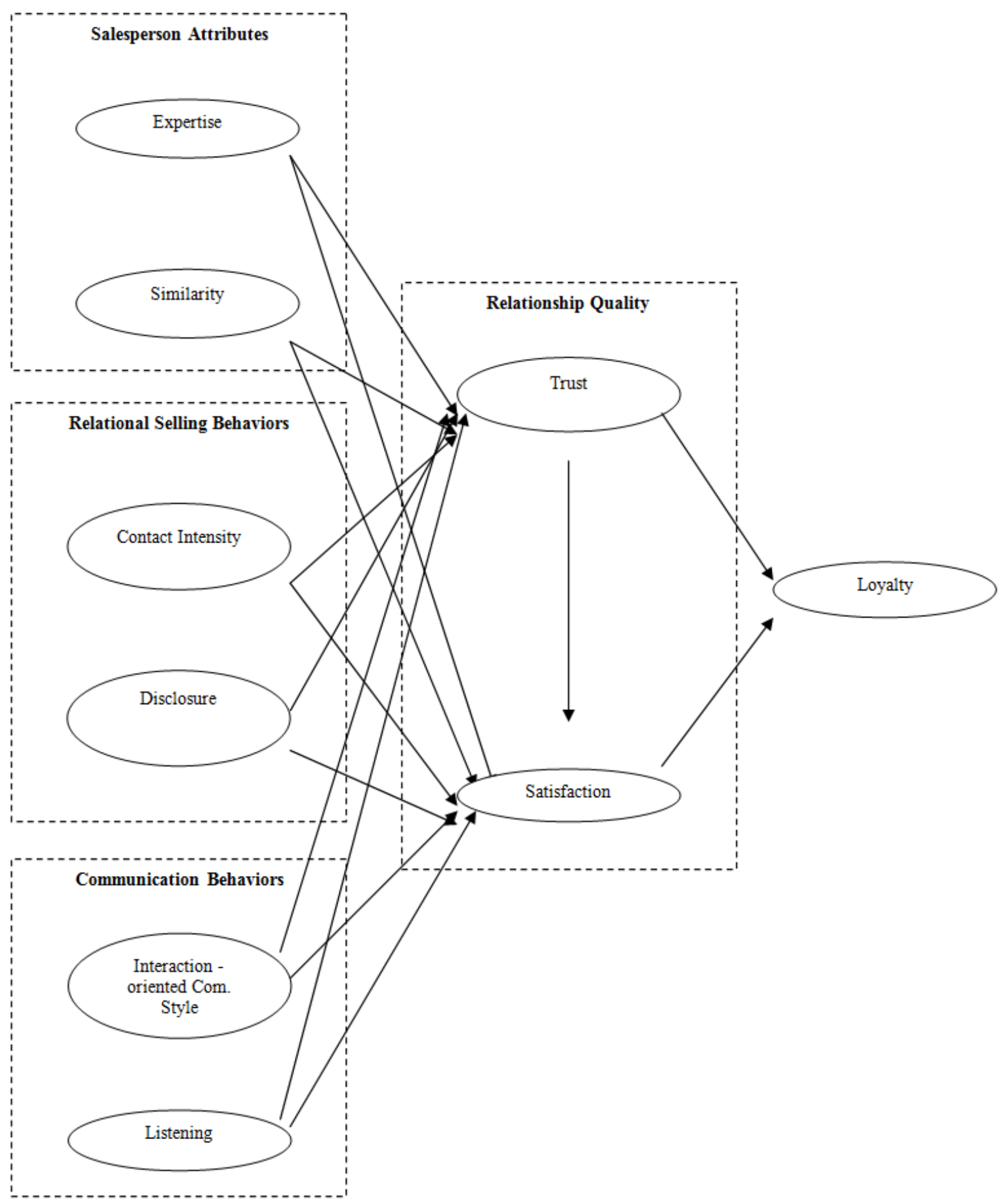

Figure 1: Conceptual Model 


\section{RELATIONSHIP QUALITY}

Relationship quality refers to the degree of appropriateness of a relationship in fulfilling the customer's needs corresponding to that relationship (Hennig-Thurau and Klee, 1997). Wray, Palmer, and Bejou (1994) have conceptualized relationship quality as comprising at least two dimensions; namely, trust and satisfaction. Past research on relationship quality has identified customer satisfaction (Anderson and Gerbing 1988; Crosby et al., 1990; Perrien and Ricard, 1995) and mutual trust (Anderson and Gerbing, 1988; Berry, 1995; Crosby et al., 1990; Doney and Cannon, 1997; Gronroos, 1990; Morgan and Hunt, 1994; Perrien and Ricard, 1995; Wilson, 1995; Wong and Sohal, 2002) as key dimensions of relationship quality. Following the conceptualization of earlier studies, relationship quality is proposed to be composed of two dimensions - satisfaction and trust.

The two dimensions of relationship quality are predicted to be positively correlated. Research in dyadic relationship has shown that the level of trustworthiness of a person influences the level of satisfaction with that person (Crosby et al., 1990; Ramsey and Sohi, 1997). Thus, the following relationship between trust and satisfaction is hypothesized for the personal life insurance service context:

H1: A customer's level of trust in a life insurance agent is positively related to his/her satisfaction level with the agent.

\section{ANTECEDENTS OF RELATIONSHIP QUALITY}

\section{Salesperson Attributes}

\section{Expertise}

A customer's perception of a salesperson's expertise reflects his or her relevant competencies associated with the goods or services (Crosby et al., 1990). According to Parasuraman, Zeithaml, and Berry (1985), competence refers to the possession of the skills and knowledge necessary to perform the service. In a study examining the use of marketing research, Moorman, Zaltman, and Deshpande (1992) find that researcher expertise is an important foundation for trust. Similarly, a study by Doney and Cannon (1997) on buyer-seller relationships shows that salesperson expertise has a positive effect on the buying firm's trust of the salesperson. Supplier representative expertise has also been found to have a strong influence on both satisfaction and trust (Smith, 1998). Applying the findings to personal life insurance service context, the following hypothesis is proposed:

H2: A personal life insurance agent's expertise is positively related to a customer's (a) trust in the agent and (b) satisfaction with the agent.

\section{Similarity}

Similarity refers to the extent to which members in a dyadic relation share similar personal attributes and characteristics (Smith, 1998) as well as common interests and values (Doney and Cannon, 1997). A central theme of the similarity-attraction theory (Bryne, 1971) is that people prefer, support, and are attracted to relationships with others who are similar. Interactions with similar people reinforce their self-esteem and maintain balance or congruity in self-identity.

Moreover, customers who perceive salespeople as similar to themselves could expect them to hold common beliefs as to what behaviors, goals and policies are appropriate. Trust and satisfaction are fostered since customers attribute benevolent intentions to salespeople whom they believe share their values (Doney and Cannon, 1997). Synthesizing all the above literature, we hypothesize the following:

H3: The similarity of a personal life insurance agent with his/her customer is positively related to the customer's (a) trust in the agent and (b) satisfaction with the agent. 


\section{Relational Selling Behaviors}

According to Crosby et al. (1990), relational selling behaviors represent a behavioral tendency exhibited by salespeople to cultivate a buyer-seller relationship and to ensure its maintenance and growth. Mutual disclosure and contact intensity have been suggested as two important behaviors in establishing and maintaining interpersonal relationships (Crosby et al., 1990).

\section{Mutual Disclosure}

Several theories, such as the trust-attraction theory and the social exchange theory (Archer, 1979), provide explanations for the reciprocity of self-disclosure. The trust-attraction hypothesis postulates that disclosing intimate information to a recipient indicates that the other is liked and trusted and that this leads the recipient to disclose, as an indicator of liking and willingness to trust the original discloser. The social exchange theory suggests that it is rewarding to receive a disclosure. When a person receives something of value, he feels obligated to return something of similar value in the form of a similar disclosure. A meta-analysis on the effect of disclosure on liking shows that individuals like people who self-disclose to them, that individuals disclose more to those they like, and that individuals like others due to having disclosed to them (Collins and Miller, 1994). Therefore, it becomes even more essential for the salesperson to lead and reciprocate the customers' disclosures effectively in order to win their satisfaction and trust. This leads to the following hypothesis:

H4: A personal life insurance agent's attempt at mutual disclosure is positively related to a customer's (a) trust in the agent and (b) satisfaction with the agent.

\section{Contact Intensity}

Contact intensity is the frequency in which salespeople communicate, either face-to-face or indirectly, with customers for personal or business purposes (Crosby et al., 1990). When salespeople have frequent contact with customers for business or social purposes, trust can be cultivated as customers can observe the salesperson's behavior in varied situations. It also provides the information to help them confidently predict the salesperson's future behavior (Doney and Cannon, 1997). An insurance agent who maintains regular contact with the customer ensures that he or she is aware of the customer's changing needs and thus will be able to react to these changes promptly. If the customer's needs have been fulfilled, he or she is more likely to be satisfied with the agent and to perceive him as being reliable and credible. Consequently, we suggest the following hypothesis:

H5: A personal life insurance agent's contact intensity is positively related to a customer's (a) trust in the agent and (b) satisfaction with the agent.

\section{Communication Behaviors}

The study of communication is fundamentally a study of relationships. Duncan and Moriarty (1998) assert that communication is the human activity that links people together and creates relationships, and the new generation marketing is most adeptly explained, understood, and accomplished with a communication-based model of relationship marketing. The roles of communication in relationship building include persuading, informing, answering and listening (Duncan and Moriarty, 1998). Research has not only shown that the ability to communicate effectively is critical to performance (Webster, 1968), but also found that communication is a major precursor of trust (Morgan and Hunt, 1994). It also positively influences employee and service evaluations, as well as satisfaction (Suprenant and Solomon, 1987). A central contention emerging from the literature on communication is that interactive communication and active listening skills are critical to the winning of the customer's satisfaction and trust. The role of communication becomes much more important in selling unsought services, such as personal life insurance. Therefore, we include communication behaviors as important antecedents of the relationship quality and attempt to investigate the effects of insurance agents' communication behaviors on relationship quality by focusing on two aspects of communication behaviors: (1) salesperson's interaction-oriented communication style and (2) salesperson listening behavior. 


\section{Interaction-Oriented Communication Style}

According to Anderson (1972), communication consists of content, code, rules and style. When an individual uses any elements of content, code, and rules over time, he develops certain "patterns" of use, or a communication style (Williams, Spiro, and Fine, 1990). An interaction-oriented communication style means that a salesperson's communication is personalized and social (Williams and Spiro, 1985). Mittal and Lassar (1996) have shown that personalization, defined as the "social content of interaction between service providers and customers," significantly influences how customers perceive overall service quality and patronage behaviors of salespeople, especially in the context of person-processing services. According to a leadership framework suggested by Bass (1960), an interaction-oriented leader is concerned with his or her group's overall harmony and uses interactionoriented communication as a mean of forming friendships, providing a sense of belonging, and helping to foster strong interpersonal relationships. Consequently, an interaction-oriented salesperson, who is more interested in establishing a personal and long-term relationship with the customer than in closing a sale, will be more likely to gain the customer's trust and satisfaction. Therefore, the following is hypothesized:

H6: Interaction-oriented communication style of a personal life insurance agent is positively related to a customer's (a) trust in the agent and (b) satisfaction with the agent.

\section{Listening}

Listening is one of the important components of communication. It is the most frequently used, yet the least understood component (Ramsey and Sohi, 1997). Lynch (1995) asserts that active listening not only helps to strengthen a relationship through establishing needs, it also bolsters the self-esteem of the customer. Salesperson's listening behavior has been defined as a cognitive process of actively sensing, interpreting, evaluating and responding to the verbal and nonverbal messages of present or potential customers (Castleberry and Shepherd, 1993). There are three components of listening: sensing, evaluating and responding (Steil, Barker, and Watson, 1983). Sensing pertains to receiving stimuli and attending to a message. Evaluating includes cognitive processes that allow the message receiver to assign meanings and value to the message. Finally, responding allows the receiver to develop and display a suitable reaction to the message (Ramsey and Sohi, 1997). When customers perceive that a salesperson is listening to them and trying hard to fulfill their needs, they feel that the salesperson is really interested in them and that he is more trustworthy (Swan and Oliver, 1991). Based on the interpersonal needs theory (Schutz, 1966), people have certain interpersonal needs that must be fulfilled in order for their interaction experience to be rewarding. If these needs, such as a feeling of being included in the communication process and a need to be liked and treated with respect, are met, they tend to stay in and build up a relationship (Anderson and Martin, 1995). Therefore, listening is suggested as a significant determinant of both satisfaction and trust.

H7: Listening behavior of a personal life insurance agent is positively related to a customer's (a) trust in the agent and (b) satisfaction with the agent.

\section{Consequence Of Relationship Quality: Loyalty}

The long-term objective of relationship marketing is to build and develop loyalty (Kurtz and Clow, 1998). Consumers express their loyalty toward a product or a service by continuing to buy from it, by saying positive things about the company to others, by making recommendations for the product or service, or by increasing business with the company in the future (Zeithaml, Berry, and Parasuraman, 1996). Dick and Basu (1994) have conceptualized loyalty as a relationship between relative attitude toward an entity (brand/service/store/vendor) and repeat patronage on it.

Customers who perceive a higher level of satisfaction with a service provider demonstrate greater commitment and therefore exhibit repurchase behavior and loyalty (Anderson and Sullivan, 1993; Fornell, 1992). Trust has been shown to be critical in maintaining continuity in conventional channel relationships (Anderson and Weitz, 1989). In the life insurance context, customers may incur high switching costs if they switch agents. The complex nature of an insurance policy may also induce customers to stay with the same agent in order to reduce the risk involved. Therefore, if satisfaction and trust have already been established, customers are even more likely to be loyal to their agents. As such, satisfaction and trust are hypothesized to be significantly related to loyalty. 
H8: A customer's trust in an insurance agent is positively related to the customer's loyalty to the agent.

H9: A customer's satisfaction with an insurance agent is positively related to the customer's loyalty to the agent.

\section{In-Group Versus Out-Group Differences}

Social identity theory (Tajfel and Turner, 1979) suggests that individuals base their self-concepts largely on group membership and differences they perceive between their in-group and all other out-groups (Hogg and Abrams, 1988). An in-group is defined as a group of people which influences an individual's behavior in a way that the individual chooses the goals of the group or subjugates his personal goals to theirs (Triandis, 1988). In-group members value their group's overall welfare over individuals' interest. Thus, they are willing to cooperate to increase or maintain group's welfare without expecting equitable returns (Triandis, 1988). Maintaining and preserving the group membership is important for in-group members.

In general, people tend to judge their in-group members more favorably than out-group members. In addition, in-group members tend to advocate for each other and afford one another special privileges that they do not afford to out-group members (Tajfel and Turner, 1979). In-group members are those who are dependable, do what the in-group expects, and are not likely to "betray" the in-group. Thus, when a person is dealing with an in-group member, he or she may be less likely to be calculative and picky than when he or she is dealing with an out-group member. Attributing favorably to in-group members and unfavorably to out-group members enhances the member's social identity as well (Kramer, 1991). This has been found to lead to in-group solidarity, cooperation and support (Hogg and Abrams, 1990), greater communication, trust and reciprocity (Lincoln and Miller, 1979), and greater satisfaction and perceived performance of relationships (Tsui and O’Reilly, 1989).

The importance of maintaining and preserving group membership and the favorable treatment for in-group members stems from the different degree of relationships between in-group and out-group members. By nature, ingroup members and out-group members are in different stages of relationship building. Certain levels of relationship are already established for in-group members. This established relationship provides the base for the preferential treatment of in-group members. At the same time, because of this already invested relationship, in-group members are expected to behave in a way that they value the group's interest over individuals' interests to protect their already invested relationships.

The different levels of relationships may also result in a different set of factors that matter more in dealing with in-group and out-group members. Factors that contribute to maintain an established relationship will be more important in dealing with in-group members, whereas factors that are critical in starting or initiating a relationship will be more important in dealing with out-group members. The antecedents of relationship quality examined earlier can be classified into two groups according to their relevance to different stages of relationship building - initiating and maintaining factors of relationship. Salesperson's attribute factors, such as expertise and similarity, are more important at the initial stage of relationship building. Contact intensity and interaction-oriented communication style are also important factors for the initial stage of a relationship. They are necessary in building a relationship. These factors are grouped as initiating factors for relation building. Compared to in-group cases, the influence of these factors on relationship quality dimensions will be stronger for out-groups because there is a need to develop a relationship first in dealing with out-group members. The tendency of favorable treatment for in-group members make the initiating factors less important for in-group members since these factors are related to insurance agent's individual qualification and effort aspects. Lack of these aspects can be tolerated by in-group members, thus produce weak effects on relationship quality constructs for in-group members.

On the other hand, mutual disclosure and listening are classified as maintaining factors of relationships. Although they are also important at the beginning stage, they become more important in maintaining the relationship. Without mutual disclosure, trust cannot be built and maintained and, eventually, groups will be dissolved. Listening will work as a glue to strengthen the group membership. Since maintaining a relationship is important for in-group members, the effects of mutual disclosure and listening are expected to be stronger for ingroup members than for out-group members. Thus, the following hypotheses are suggested: 
H10: The influence of (a) expertise, (b) similarity, (c) contact intensity, and (d) interaction-oriented communication style will be stronger when the insurance agent is an out-group member than when the agent is an in-group member.

H11: The influence of (a) mutual disclosure and (b) listening will be stronger when the insurance agent is an ingroup member than when the agent is an out-group member.

Since the level of trust for in-group members will be higher than the out-group members, it is expected that the effect of trust will be stronger for in-group members than out-group members for the relationship among relationship quality dimensions and loyalty. Therefore, we hypothesize the following:

H12: The influence of trust on (a) satisfaction and (b) loyalty will be stronger when the insurance agent is an ingroup member than when the agent is an out-group member.

\section{METHOD}

Sample

A total of 286 questionnaires are collected from a convenient sample of Chinese customers who purchased life insurance policies from life insurance agents. The sample is evenly distributed in terms of gender, being $52.1 \%$ male and $47.9 \%$ female. However, it is slightly skewed toward the younger and more educated respondents.

The classification between the in-group and the out-group is made by following Triandis' (1988) definition. According to him, in-group members typically pertain to kin, romantic partner and close friends while out-group members refer to those who are not in the in-group (Triandis, 1988). Operationalizing Triandis' classification to this study, life insurance customers, who are family members, relatives, or close friends of their agents are classified as the in-group members while customers who regard their agents as acquaintances, business associates, or strangers are classified as the out-group members. This classification results in 111 in-group and 175 out-group cases.

\section{Measures}

All measures used in this study are drawn from past studies and necessary modifications are made to adapt them to the specific context of the study. The expertise scale is adapted from Crosby et al.'s (1990) salesperson expertise index and the attributed expert power index of Comer (1984). Similarity is measured by seven items adapted from Crosby et al.'s (1990) salesperson similarity index. Mutual Disclosure is measured by six items that are adapted from the agent disclosure indices of Crosby et al. (1990). The measure for Contact Intensity is comprised of four items adapted from Crosby et al.'s (1990) interaction intensity index. The six items for Interaction-oriented Communication Style are adapted from the salesperson's interaction style dimension of Williams and Spiro (1985). The eight items for Listening are adapted from the salesperson's listening scale of Ramsey and Sohi (1997). Satisfaction is measured by three items adapted from scales used by Ryan, Buzas, and Ramaswamy (1995). The six items for trust are adapted from Crosby et al. (1990) and Doney and Cannon (1997). The five items for loyalty are adapted from Dick and Basu (1994) and Zeithaml et al. (1996). All items are measured on a 5-point Likert scale with strong agree/strong disagree as the scale anchors.

\section{Reliability And Validity Of Measures}

The measures are validated by confirmatory factor analysis using AMOS 5. The confirmatory measurement model has $\chi^{2}{ }_{1139}=2100(\mathrm{p}<.00)$, CFI of .92, TLI of .91 and RMSEA of .05 , which indicates good fit of the measurement model. The convergent validity of the individual scales is assessed by the estimated factor loadings of the measurement model. All factor loadings are greater than the recommended 0.4 cut-off value and are statistically significant (Nunnally and Berstein, 1994). The internal consistency of the measurement models is further assessed by the reliabilities and average variance extracted (Fornell and Larcker, 1981). All the reliabilities are greater than the recommended level of 0.7 (Nunnally and Berstein, 1994) and the average variances extracted for all measures are greater than the recommended level of 0.5 (Baggozi and Yi, 1988). 
The discriminant validity of the measures is then assessed by examining pairs of constructs in a series of two-factor confirmatory factor models $-\chi^{2}$ difference tests between a model that constrains the correlation equal to 1 and a model that does not place such a constraint are conducted (Gerbing and Anderson, 1988). For each pair of constructs, the $\chi^{2}$ value for the constrained model is significantly greater than the $\chi^{2}$ value for the unconstrained model ( $\mathrm{p}<.01$ ), providing supporting evidences for the discriminant validity of the measures. Analysis results on the measurement model and basic statistics for the constructs are summarized in Tables 1 and 2.

Table 1: Measurement Model And Confirmatory Analysis Results

\begin{tabular}{|c|c|c|c|c|}
\hline \multirow{2}{*}{ Constructs \& Items } & \multicolumn{2}{|c|}{ CFA } & \multirow{2}{*}{$\begin{array}{l}\text { Average } \\
\text { Construct } \\
\text { Reliability }\end{array}$} & \multirow{2}{*}{$\begin{array}{c}\text { Average } \\
\text { Variance } \\
\text { Extracted }\end{array}$} \\
\hline & Loadings & t-value & & \\
\hline Expertise $($ Cronbach's Alpha $=.90)$ & & & .90 & .65 \\
\hline $\begin{array}{l}\text { 1. My agent has a good knowledge of the insurance market } \\
\text { and life insurance matters. }\end{array}$ & .78 & & & \\
\hline $\begin{array}{l}\text { 2. My agent gives me a thorough explanation of the various } \\
\text { kinds of policies. }\end{array}$ & .79 & 13.99 & & \\
\hline 3. My agent is experienced in financial planning. & .80 & 14.30 & & \\
\hline 4. My agent provides sound advice and recommendations. & .82 & 14.65 & & \\
\hline 5. My agent is highly qualified. & .83 & 14.87 & & \\
\hline Similiarity $($ Cronbach's Alpha $=.89)$ & & & .90 & .56 \\
\hline 1. Appearance (i.e., attire, style) & .75 & & & \\
\hline 2. Mannerism/Behavior & .85 & 14.68 & & \\
\hline 3. Personality & .90 & 15.59 & & \\
\hline 4. Speech & .81 & 13.89 & & \\
\hline 5. Personal values & .70 & 11.85 & & \\
\hline 6. Age & .52 & 8.72 & & \\
\hline 7. Interests/hobbies & .63 & 10.66 & & \\
\hline Contact Intensity (Cronbach's Alpha =.88) & & & .88 & .65 \\
\hline $\begin{array}{l}\text { 1. My agent contacts me to make changes in the policy to } \\
\text { better serve my needs. }\end{array}$ & .79 & & & \\
\hline $\begin{array}{l}\text { 2. My agent contacts me to stay in touch and make sure that I } \\
\text { am still satisfied with the policy. }\end{array}$ & .87 & 16.07 & & \\
\hline $\begin{array}{l}\text { 3. My agent contacts me to describe new types of policies that } \\
\text { have become available. }\end{array}$ & .75 & 13.33 & & \\
\hline $\begin{array}{l}\text { 4. My agent contacts me to keep up with the changes in my } \\
\text { family and insurance needs. }\end{array}$ & .80 & 14.40 & & \\
\hline
\end{tabular}


Table 1: Measurement Model And Confirmatory Analysis Results (Continued)

\begin{tabular}{|c|c|c|c|c|}
\hline \multirow[b]{2}{*}{ Constructs \& Items } & \multicolumn{2}{|c|}{ CFA } & \multirow{2}{*}{$\begin{array}{l}\text { Average } \\
\text { Construct } \\
\text { Reliability }\end{array}$} & \multirow{2}{*}{$\begin{array}{l}\text { Average } \\
\text { Variance } \\
\text { Extracted }\end{array}$} \\
\hline & Loadings & t-value & & \\
\hline Disclosure $($ Cronbach's Alpha $=.92)$ & & & .92 & .67 \\
\hline $\begin{array}{l}\text { 1. My agent tells me about his/her job (e.g., responsibilities, } \\
\text { likes and dislikes for occupation). }\end{array}$ & .77 & & & \\
\hline 2. My agent confides in me about his/her values and beliefs. & .86 & 15.68 & & \\
\hline $\begin{array}{l}\text { 3. My agent confides in me about his/her background, } \\
\text { personal life and family situation. }\end{array}$ & .80 & 14.39 & & \\
\hline $\begin{array}{l}\text { 4. My agent tells me about financial mistakes he/she made in } \\
\text { the past. }\end{array}$ & .81 & 14.58 & & \\
\hline $\begin{array}{l}\text { 5. My agent confides in me about his/her financial situation } \\
\text { and dealings. }\end{array}$ & .85 & 15.51 & & \\
\hline $\begin{array}{l}\text { 6. My agent confides in me about his/her own financial goals } \\
\text { and objectives, even hopes and dreams for the future. }\end{array}$ & .81 & 14.65 & & \\
\hline $\begin{array}{l}\text { Interaction Oriented Communication Style (Cronbach's } \\
\text { Alpha }=.92 \text { ) }\end{array}$ & & & .92 & 67 \\
\hline 1. My agent is easy to talk with & .73 & & & \\
\hline $\begin{array}{l}\text { 2. My agent is interested in me not only as a customer, but } \\
\text { also as a person. }\end{array}$ & .82 & 13.80 & & \\
\hline 3. My agent is genuinely enjoys helping me. & .90 & 15.26 & & \\
\hline 4. My agent is friendly towards me. & .81 & 13.63 & & \\
\hline 5. My agent is cooperative person. & .85 & 14.42 & & \\
\hline 6. My agent tries $t$ establish a personal relationship with me. & .78 & 13.08 & & \\
\hline Listening (Cronbach's Alpha $=.88$ ) & & & .89 & .50 \\
\hline 1. My agent maintains eye contact. & .79 & & & \\
\hline 2. My agent focuses only on me. & .73 & 13.25 & & \\
\hline $\begin{array}{l}\text { 3. My agent's nonverbal gestures suggest he/she is listening to } \\
\text { me. }\end{array}$ & .79 & 14.52 & & \\
\hline 4. My agent asks for more details. & .61 & 10.62 & & \\
\hline 5. My agent paraphrases my questions. & .44 & 7.31 & & \\
\hline $\begin{array}{l}\text { 6. My agent offers relevant information to the questions I } \\
\text { asked. }\end{array}$ & .74 & 13.37 & & \\
\hline 7. My agent uses full sentences instead of saying yes or no. & .67 & 11.91 & & \\
\hline 8. My agent answers at appropriate times. & .80 & 14.71 & & \\
\hline
\end{tabular}


Table 1: Measurement Model And Confirmatory Analysis Results (Continued)

\begin{tabular}{|c|c|c|c|c|}
\hline \multirow{2}{*}{ Constructs \& Items } & \multicolumn{2}{|c|}{ CFA } & \multirow{2}{*}{$\begin{array}{c}\text { Average } \\
\text { Construct } \\
\text { Reliability }\end{array}$} & \multirow{2}{*}{$\begin{array}{c}\text { Average } \\
\text { Variance } \\
\text { Extracted }\end{array}$} \\
\hline & Loadings & t-value & & \\
\hline Trust (Cronbach's Alpha $=.89$ ) & & & .90 & .60 \\
\hline 1. I find my agent to be sincere. & .86 & & & \\
\hline 2. My agent is trustworthy. & .88 & 20.18 & & \\
\hline 3. My agent puts the customers' interests before his/her own. & .73 & 14.61 & & \\
\hline 4. My agent is reliable. & .80 & 16.86 & & \\
\hline $\begin{array}{l}\text { 5. My agent does not seem to be concerned with my needs. } \\
\text { ( ) }\end{array}$ & .73 & 14.62 & & \\
\hline $\begin{array}{l}\text { 6. I find it necessary to be cautious of my agent when dealing } \\
\text { with him/her. ( ) }\end{array}$ & .59 & 10.92 & & \\
\hline Satisfaction (Cronbach's Alpha $=.93$ ) & & & .94 & .83 \\
\hline 1. General satisfaction. & .92 & & & \\
\hline 2. Meeting expectation. & .92 & 26.52 & & \\
\hline 3. Closeness to ideal agent. & .89 & 24.29 & & \\
\hline Loyalty $($ Cronbach's Alpha $=.95)$ & & & .95 & .79 \\
\hline $\begin{array}{l}\text { 1. I will consider my agent my first choice to buy other } \\
\text { policies. }\end{array}$ & .87 & & & \\
\hline 2. I will say positive things about my agent to other people. & .87 & 20.95 & & \\
\hline $\begin{array}{l}\text { 3. I will recommend my agent to someone who seeks my } \\
\text { advice. }\end{array}$ & .92 & 23.49 & & \\
\hline $\begin{array}{l}\text { 4. I will encourage my friends and relatives to buy insurance } \\
\text { from my agent. }\end{array}$ & .86 & 20.26 & & \\
\hline $\begin{array}{l}\text { 5. I will contact my agent again if I want to upgrade the } \\
\text { policy to better serve my needs. }\end{array}$ & .91 & 22.93 & & \\
\hline
\end{tabular}

Note: $\chi_{1139}^{2}=2100 ; \mathrm{CFI}=.92 ; \mathrm{TLI}=.91 ; \mathrm{RMSEA}=.05$

Table 2: Means, Standard Deviation, And Correlations Of The Constructs

\begin{tabular}{|c|c|c|c|c|c|c|c|c|c|c|c|}
\hline \multirow{2}{*}{ Constructs } & \multirow{2}{*}{ Mean } & \multirow{2}{*}{ S.D. } & \multicolumn{9}{|c|}{ Correlations } \\
\hline & & & V1 & V2 & V3 & V4 & V5 & V6 & V7 & V8 & V9 \\
\hline V1. Expertise & 3.58 & .80 & - & & & & & & & & \\
\hline V2. Similarity & 2.81 & .83 & $.33 *$ & - & & & & & & & \\
\hline V3. Contact intensity & 3.29 & .97 & $.51 *$ & $.35 *$ & - & & & & & & \\
\hline V4. Disclosure & 2.46 & .95 & $.39 *$ & $.40^{*}$ & $.57 *$ & - & & & & & \\
\hline V5. Interaction-oriented com. style & 3.71 & .80 & $.57 *$ & $.40^{*}$ & $.60 *$ & $.51 *$ & - & & & & \\
\hline V6. Listening & 3.57 & .65 & $.60 *$ & $.32 *$ & $.56^{*}$ & $.48 *$ & $.72 *$ & - & & & \\
\hline V7. Trust & 3.67 & .75 & $.54 *$ & $.27 *$ & $.54 *$ & $.49 *$ & $.76^{*}$ & $.66^{*}$ & - & & \\
\hline V8. Satisfaction & 3.41 & .88 & $.64 *$ & $.37 *$ & $.65^{*}$ & $.56^{*}$ & $.73 *$ & $.67 *$ & $.78 *$ & - & \\
\hline V9. Loyalty & 3.45 & .99 & $.59 *$ & $.40^{*}$ & $.60^{*}$ & $.53^{*}$ & $.76^{*}$ & $.62 *$ & $.78^{*}$ & $.86^{*}$ & - \\
\hline
\end{tabular}

*: Correlation is significant at $\alpha=.01$ level

\section{RESULTS}

The hypothesized model is tested using AMOS 5 with the maximum likelihood method. H1 to H9 are first tested with all samples without dividing them into the in-group and the out-group. The structural model has a significant $\chi_{2290}^{2}$ value of $2122.6(\mathrm{p}<.01)$. CFI is .92, TLI is .91 and RMSEA is .05. These statistics indicate generally a good level of fit. Table 3 summarizes the results of structural model parameter estimates and assessment of hypothesized relationships. Among salesperson attribute factors, expertise has significant influence on both trust $(b=.10, p<.05)$ and satisfaction $(b=.18, p<.01)$, whereas similarity's influence is not significant on either trust $(b=-$ 
$.07, \mathrm{p}>.05)$ or satisfaction $(\mathrm{b}=.05, \mathrm{p}>.05)$. Thus, $\mathrm{H} 2(\mathrm{a})$ and $\mathrm{H} 2(\mathrm{~b})$ are supported, but $\mathrm{H} 3(\mathrm{a})$ and $\mathrm{H} 3(\mathrm{~b})$ are not. Among relational selling behavior factors, contact intensity has a significant influence on satisfaction $(b=.20$, $\mathrm{P}<.01$ ), but not on trust ( $\mathrm{b}=.05, \mathrm{p}>.05$ ). Thus, H4(b) is supported, but H4(a) is not. Mutual disclosure shows the opposite pattern of contact intensity. It has a significant influence on trust $(b=.09, p<.05)$, but not on satisfaction ( $b=.08, p>.05$ ), supporting H5(a), but not H5(b). Among communication behavior factors, interaction-oriented communication style has a significant influence on trust $(b=.66, p<.01)$, but not on satisfaction $(b=.02, p>.05)$. Thus, H6(a) is supported, but not H6(b). Listening's influence is not significant on both trust $(b=.10, p>.05)$ and satisfaction ( $b=.01, \mathrm{p}>.05)$, failing to support both $\mathrm{H} 7(\mathrm{a})$ and $\mathrm{H} 7(\mathrm{~b})$. Trust has significant influence on both satisfaction $(\mathrm{b}=.53, \mathrm{p}<.01)$ and loyalty $(\mathrm{b}=.25, \mathrm{p}<.01)$ as predicted. Satisfaction also shows the predicted significant influence on loyalty $(\mathrm{b}=.70, \mathrm{p}<.01)$. Thus, $\mathrm{H} 1, \mathrm{H} 8$, and $\mathrm{H} 9$ are supported.

Table 3: Structural Model Estimates And Assessment Of Hypothesized Relationships For All Groups*

\begin{tabular}{|c|c|c|c|c|}
\hline \multirow{2}{*}{ Relationships among Constructs } & \multirow{2}{*}{$\begin{array}{l}\text { Hypothesized } \\
\text { relationship }\end{array}$} & \multicolumn{3}{|c|}{ In-group } \\
\hline & & $\begin{array}{c}\text { Standardized } \\
\text { estimates }\end{array}$ & t-value & $\mathbf{P}^{* * *}$ \\
\hline \multicolumn{5}{|l|}{ Salesperson Attributes } \\
\hline Expertise $\rightarrow$ Trust & + & .10 & 1.73 & $<.05$ \\
\hline Expertise $\rightarrow$ Satisfaction & + & .18 & 3.52 & $<.01$ \\
\hline Similarity $\rightarrow$ Trust & + & -.07 & -1.60 & n.s. \\
\hline Similarity $\rightarrow$ Satisfaction & + & .05 & 1.16 & n.s. \\
\hline \multicolumn{5}{|l|}{ Relational Selling Behaviors } \\
\hline Contact intensity $\rightarrow$ Trust & + & .05 & .74 & n.s. \\
\hline Contact intensity $\rightarrow$ Satisfaction & + & .20 & 3.33 & $<.01$ \\
\hline Disclosure $\rightarrow$ Trust & + & 09 & 1.75 & $<.05$ \\
\hline Disclosure $\rightarrow$ Satisfaction & + & .08 & 1.61 & n.s. \\
\hline \multicolumn{5}{|l|}{ Communication Behaviors } \\
\hline$\overline{\text { Interaction-oriented style } \rightarrow \text { Trust }}$ & + & .66 & 7.49 & $<.01$ \\
\hline Interaction-oriented style $\rightarrow$ Satisfaction & + & .02 & .27 & n.s. \\
\hline Listening $\rightarrow$ Trust & + & .10 & 1.31 & n.s. \\
\hline Listening $\rightarrow$ Satisfaction & + & .01 & .18 & n.s. \\
\hline \multicolumn{5}{|l|}{ Relationship Quality Consequence } \\
\hline Trust $\rightarrow$ Satisfaction & + & .53 & 6.33 & $<.01$ \\
\hline Trust $\rightarrow$ Loyalty & + & .25 & 3.60 & $<.01$ \\
\hline Satisfaction $\rightarrow$ Loyalty & + & .70 & 9.66 & $<.01$ \\
\hline
\end{tabular}

* Model fit: $\chi^{2}=2122.59, \mathrm{df}=1145 ; \mathrm{CFI}=.92, \mathrm{TLI}=.91, \mathrm{RMSEA}=.05$

$* * t$ value of 1.645 is used to test significance level of $\alpha=.05$ because of one-tail test.

Next, the hypothesized relationships are tested separately between the in-group and the out-group conditions. This separate assessment will show the difference between the in-group and the out-group conditions more clearly in addition to the tests of differences in the magnitudes of coefficients in the structural model. The multi-group structural model has a significant $\chi_{2290}^{2}$ value of 3705.9 ( $\left.\mathrm{p}<.01\right)$. CFI is .87 , TLI is .86 and RMSEA is .05. These statistics indicate generally a good fit level of the model. The influence of expertise of insurance agent on trust is significant for the in-group condition $(b=.32, \mathrm{p}<.01)$, but not for the out-group condition $(b=-.-.15, \mathrm{p}>.05)$. Its influence on satisfaction has the reverse pattern. That is, the influence is not significant for the in-group condition $(b=.07, p>.05)$, but is significant for the out-group condition $(b=.30, p<.01)$. Thus, H2(a) is supported for the ingroup condition and $\mathrm{H} 2$ (b) is supported for the out-group condition, respectively. The influence of insurance agent's similarity to customer on trust is not significant for both the in-group $(b=-.09 ; p>.05)$ and the out-group conditions $(b=-.06, p>.05)$. Thus, H3(a) is not supported for both groups. The influence of similarity on satisfaction is significant for the in-group condition $(b=.12 ; \mathrm{p}<.05)$, but not for the out-group condition $(b=.00, p>.05)$. Thus, the support for H3(b) is only observed for the in-group condition.

As for the relationships between relational selling behaviors and relationship quality components, contact intensity has a significant impact on trust for the out-group condition $(b=19, p<.05)$, but not for the in-group 
condition ( $b=-.13, p>.05)$. Thus, H4(a) is only supported in the out-group condition. Its influence on satisfaction is significant for both conditions $(b=.21, \mathrm{p}<.01$ for the in-group condition and $b=.14, \mathrm{p}<.05$ for the out-group condition), supporting $\mathrm{H} 4(\mathrm{~b})$. The influence of disclosure on both trust and satisfaction is not significant for both conditions. Thus, H5(a) and H5(b) are not supported.

Among communication behaviors, interaction-oriented communication style has a significant impact on trust for both the in-group condition ( $\mathrm{b}=.47, \mathrm{p}<.01)$ and the out-group condition $(\mathrm{b}=.80, \mathrm{p}<.01)$, supporting H6(a). However, its impact on satisfaction is not significant for both conditions, failing to support H6(b). Listening has a significant influence on trust for the in-group condition $(b=.22, \mathrm{p}<.05)$, but not for the out-group condition. Thus, H7(a) is supported in the in-group condition only. Listening behavior's influence on satisfaction is not significant for both conditions. Thus, $\mathrm{H} 7(\mathrm{~b})$ is not supported.

As for the relationships between relationship quality components and their influence on loyalty, significant influence of trust on satisfaction is observed for both conditions $(b=.78, p<.01$ for the in-group condition and $b=.47$, $\mathrm{p}<.01$ for the out-group condition), supporting H1. The influence of satisfaction on loyalty is also significant for both groups as predicted $(b=.65, p<.01$ for the in-group condition and $b=.77, p<.01$ for the out-group condition), supporting H9. However, the influence of trust on loyalty is only significant for the out-group condition $(b=.18$, $\mathrm{p}<.05)$, but not for the in-group condition $(\mathrm{b}=.24, \mathrm{p}>.05)$. Therefore, the support for $\mathrm{H} 8$ is observed only in the outgroup condition. The results of the separate tests of the hypotheses between the in-group and the out-group conditions reveal somewhat different patterns of the relationship. Except for similarity, initiating factors, such as expertise, contact intensity and interaction-oriented communication style, are found to be significant predictors for the relationship quality factors in the out-group condition, as predicted. The maintaining factors are not found to be significant predictors. For the in-group condition, among the maintaining factors, listening behavior, but not mutual disclosure, is found to be a significant predictor for the relationship quality. In addition, all the initiating factors are found to be influential factors.

The differential influences of each construct between the in-group and the out-group relationship conditions are further examined using $\chi^{2}$ difference tests on parameters using structural equation modeling (Bagozzi, Yi, and Philips, 1991). First, equality of all structural model estimates is assessed by comparing an equality-constrained model where each parameter is set to be equal for both in-group and out-group conditions to an unconstrained model where all parameters are estimated freely without equality constraint. The $\chi^{2}$ difference is $33.5(\mathrm{df}=12)$ and significant, thus indicating that the structural model parameters between the in-group and the out-group conditions are not equal at the overall level.

Next, the difference in each parameter is tested by comparing the unconstrained model against an equality constrained model where only the parameter being tested is set to be equal for both in-group and out-groups. Significant differences are observed in five out of 15 parameters. Among the five significantly different parameters, only one is in the opposite direction of the hypothesis. Among the remaining ten insignificant parameters, we have directional support for seven parameters. Detailed test results are as follows. The differences in the effect of expertise on trust and satisfaction are significant, but the difference in the effect on trust is in opposite direction of the hypothesis while the difference in the effect on satisfaction is consistent with the hypothesis. Thus, H10(a) is partially supported. The differences in the effect of similarity on trust and satisfaction are not significant, failing to support H1O(b). The difference in the effect of contact intensity on trust is significant, as predicted, but the difference on satisfaction is not significant, providing partial support for H10(c). The difference in the effect of interaction-oriented communication style on trust is significant as predicted. Although it fails to reach the level of significance, the difference in effect of interaction-style on satisfaction is in the same direction of the hypothesis. Thus there are partial and directional supports for H10(d). The differences in the effect of disclosure on trust and satisfaction are not significant. Thus, H11(a) is not supported. Although the differences in the effect of listening on trust and satisfaction are not significant, the directions of differences are all in the same direction as the hypothesis, providing a directional support for H11(b). The difference in the effect of trust on satisfaction is significant, as predicted, supporting H12(a). The difference in the effect of trust on loyalty is not significant, but the difference is in the same direction as the hypothesis, providing a directional support for H12(a). Table 4 summarizes the results of structural model parameter estimates and assessment of differences between the in-group and the out-group conditions. 
Table 4: Structural Model Estimates And Assessment Of Differences Between In-Group And Out-Group*

\begin{tabular}{|c|c|c|c|c|c|c|c|}
\hline \multirow{2}{*}{ Relationships among Constructs } & \multicolumn{3}{|c|}{ In-group } & \multirow{2}{*}{$\begin{array}{c}\text { Out-group } \\
\begin{array}{c}\text { Standardized } \\
\text { estimates }\end{array}\end{array}$} & \multirow[b]{2}{*}{ t-value } & \multirow[b]{2}{*}{$\mathbf{P} * *$} & \multirow{2}{*}{$\begin{array}{c}\text { Differences in estimates between in- } \\
\text { group and out-group } \\
\left(\Delta \chi^{2} \text { test }\right)+\end{array}$} \\
\hline & $\begin{array}{c}\text { Standardized } \\
\text { estimates }\end{array}$ & t-value & $\mathbf{P} * *$ & & & & \\
\hline $\begin{array}{l}\text { Salesperson Attributes } \\
\text { Expertise } \rightarrow \text { Trust } \\
\text { Expertise } \rightarrow \text { Satisfaction } \\
\text { Similarity } \rightarrow \text { Trust } \\
\text { Similarity } \rightarrow \text { Satisfaction }\end{array}$ & $\begin{array}{l}.32 \\
.07 \\
-.09 \\
.12\end{array}$ & $\begin{array}{c}3.56 \\
.81 \\
-1.18 \\
1.80\end{array}$ & $\begin{array}{l}<.01 \\
\text { n.s. } \\
\text { n.s. } \\
<.05\end{array}$ & $\begin{array}{l}-.15 \\
.30 \\
-.06 \\
.00\end{array}$ & $\begin{array}{c}-1.61 \\
3.56 \\
-1.05 \\
.08\end{array}$ & $\begin{array}{l}\text { n.s. } \\
<.01 \\
\text { n.s. } \\
\text { n.s. }\end{array}$ & $\begin{array}{l}<.01 \\
<.01 \\
\text { n.s. } \\
\text { n.s. }\end{array}$ \\
\hline $\begin{array}{l}\text { Relational Selling Behaviors } \\
\text { Contact intensity } \rightarrow \text { Trust } \\
\text { Contact intensity } \rightarrow \text { Satisfaction } \\
\text { Disclosure } \rightarrow \text { Trust } \\
\text { Disclosure } \rightarrow \text { Satisfaction } \\
\end{array}$ & $\begin{array}{l}-.13 \\
.21 \\
15 \\
.05 \\
\end{array}$ & $\begin{array}{l}-1.36 \\
2.42 \\
1.62 \\
.58 \\
\end{array}$ & $\begin{array}{l}\text { n.s. } \\
<.01 \\
\text { n.s. } \\
\text { n.s. }\end{array}$ & $\begin{array}{l}.19 \\
.14 \\
.01 \\
.10 \\
\end{array}$ & $\begin{array}{l}2.02 \\
1.77 \\
.10 \\
1.63 \\
\end{array}$ & $\begin{array}{l}<.05 \\
<.05 \\
\text { n.s. } \\
\text { n.s. }\end{array}$ & $\begin{array}{l}<.05 \\
\text { n.s. } \\
\text { n.s. } \\
\text { n.s. }\end{array}$ \\
\hline $\begin{array}{l}\text { Communication Behaviors } \\
\text { Interaction-oriented style } \rightarrow \text { Trust } \\
\text { Interaction-oriented style } \rightarrow \text { Satisfaction } \\
\text { Listening } \rightarrow \text { Trust } \\
\text { Listening } \rightarrow \text { Satisfaction }\end{array}$ & $\begin{array}{l}.47 \\
-.10 \\
.22 \\
-.01\end{array}$ & $\begin{array}{l}4.04 \\
-.88 \\
1.84 \\
-.12\end{array}$ & $\begin{array}{l}<.01 \\
\text { n.s. } \\
<.01 \\
\text { n.s. }\end{array}$ & $\begin{array}{c}.80 \\
.09 \\
.05 \\
-.05\end{array}$ & $\begin{array}{c}5.89 \\
.61 \\
.46 \\
-.51\end{array}$ & $\begin{array}{l}<.01 \\
\text { n.s. } \\
\text { n.s. } \\
\text { n.s. }\end{array}$ & $\begin{array}{l}<.01 \\
\text { n.s. } \\
\text { n.s. } \\
\text { n.s. }\end{array}$ \\
\hline $\begin{array}{l}\text { Relationship Quality Consequence } \\
\text { Trust } \rightarrow \text { Satisfaction } \\
\text { Trust } \rightarrow \text { Loyalty } \\
\text { Satisfaction } \rightarrow \text { Loyalty }\end{array}$ & $\begin{array}{l}.78 \\
.24 \\
.65\end{array}$ & $\begin{array}{l}5.24 \\
1.63 \\
4.19\end{array}$ & $\begin{array}{l}<.01 \\
\text { n.s. } \\
<.01\end{array}$ & $\begin{array}{l}.47 \\
.18 \\
.77\end{array}$ & $\begin{array}{l}4.04 \\
2.31 \\
8.97\end{array}$ & $\begin{array}{l}<.01 \\
<.01 \\
<.01\end{array}$ & $\begin{array}{l}<.05 \\
\text { n.s. } \\
\text { n.s. }\end{array}$ \\
\hline
\end{tabular}

* Multigroup model fit: $\chi^{2}=3705.91, \mathrm{df}=2290 ; \mathrm{CFI}=.87, \mathrm{TLI}=.86, \mathrm{RMSEA}=.05$

** $\mathrm{t}$ value of 1.645 is used to test significance level of $\alpha=.05$ because of one-tail test.

$+\Delta \chi^{2}$ test between the unconstrained model with all estimates being freely estimated and the constrained model with equality constraint that specify the parameter being tested to be equal for both groups. 


\section{DISCUSSIONS}

In this study, we attempt to expand Crosby et al.'s (1990) relationship quality model by incorporating communication behaviors as antecedents of relationship quality to find a more appropriate model of relationship quality in the personal life insurance service context. We also attempt to find differences between in-group and outgroup cases of insurance agents and their customer relationships.

The analyses on all samples find that expertise, contact intensity, mutual disclosure, and interactionoriented communication style are significant predictors of relationship quality dimensions as predicted. But, similarity and mutual disclosure are not significant in influencing relationship quality dimensions. The relationships among the relationship quality dimensions and loyalty are found to be significant as predicted.

When analyzed separately, the pattern of the relationships turns out to be somewhat different between the in-group and the out-group conditions. As predicted, the factors that can be regarded as important in the initiating a relationship are found to be significant predictors of relationship quality for the out-group condition. For the ingroup condition, however, all factors except for the mutual disclosure, are found to be influential factors to the relationship quality. More detailed differences are explained as follows. First, expertise of an agent has a significant influence on satisfaction when the agent is the out-group member as predicted. But, its effect is not significant on trust. Expertise also has a significant influence on relationship quality when the agent is an in-group member; but the effect is not on satisfaction, rather on trust. These results suggest that the increasing level of expertise of an agent would help to increase the level of satisfaction for out-group customers whereas it would increase the level of trust for in-group customers. In the case of in-group member relations, they may tolerate lack of expertise of their ingroup agents; but if the agents posses expertise, it may work as a motivating factor to increase the level of trust on the relationship.

Second, contrary to the hypothesis, similarity between agent and customer does not have any significant influence on both relationship quality dimensions for the out-group condition. This implies that similarity of an agent is not an essential factor of service delivery for out-group customers. On the other hand, similarity is found to be a significant influencer in the in-group condition. Like expertise, similarity also seems to work as a motivating factor in the in-group condition. Its influence is, however, not on trust, but on satisfaction of the relationship.

Third, maintaining intense contact with a customer turns out to be an important factor in building relationship quality with out-group members because it influences both components of the relationship quality. With in-group members, contact intensity of an agent influences satisfaction, but not trust. A pre-existing level of trust due to the in-group ties may be attributed to its insignificant influence on trust.

Fourth, the influence of an agent's disclosure on relationship quality is not significant for both in-group and out-group conditions. A possible explanation could be that when the agent is an in-group member, the agent's disclosure about himself may not be necessary because the customer already knows the agent. When the agent is an out-group member, the customer may not expect his agent to reveal much about himself.

Fifth, the effect of communication behaviors of an insurance agent turns out to be consistent with the prediction. More specifically, interaction-oriented communication style has a positive impact on trust building in both in-group and out-group conditions. The result of parameter comparison shows that the effect is stronger in the out-group condition than in the in-group condition. Listening behavior has a positive impact on trust only in the ingroup condition, which indicates listening behavior is more important in the in-group condition to maintain the relationship as predicted. However, an interesting finding is that the effect of both interaction-oriented communication style and listening behavior is focused on trust building, not on satisfaction boosting in both the ingroup and the out-group conditions. This finding is in line with Ramsey and Sohi's (1997) finding where they found a positive association between listening perception and trust in the salesperson, but not between listening perception and satisfaction. Therefore, when a customer feels that an insurance agent is listening to what he/she is saying, it enhances their trust in that agent. The increased level of trust, in turn, increases satisfaction level, suggesting indirect influence of communication behavior on satisfaction through trust. 
Although it is hypothesized that the factors related to initiating relationship would be more influential in the out-group condition and that the factors related to maintaining relationship would be more influential in the in-group condition, the hypothesized pattern is only supported for the out-group condition. For the in-group condition, all factors seem to be significant antecedents for relationship quality, except for mutual disclosure. In other words, for in-group relationships, both initiating and maintaining antecedents are important for managing the relationship quality. Each antecedent factor's influence on the key two dimensions of relationship quality; i.e., trust and satisfaction, turns out to be different between the in-group and the out-group conditions, which reflects a complexity of relationship quality phenomenon.

We also find a different pattern of relationship between relationship quality dimensions and loyalty. When the insurance agent is an in-group member, there is a tendency for trust to positively influence the customer's satisfaction with the agent. Satisfaction with the agent, in turn, positively influences loyalty to the agent. When an insurance agent is an out-group member, trust positively influences satisfaction and both trust and satisfaction have positive influences on loyalty, as predicted. A reason for this difference could be attributed to the fact that customers who belong to the in-group already have substantial amount of trust in their agents from their pre-established ingroup ties. Since this pre-existing level of trust is formed out of the insurance agent-customer relationship context, its direct influence on customer's loyalty to the agent could be weak. Rather, its influence follows an indirect route through satisfaction with the agent. On the other hand, when the agent is an out-group member, there is no preexisting level of trust. The trust has to be built in the new relationship context of insurance agent and customer. Therefore, the newly formed trust is in the life insurance agent-customer context and has a direct influence on loyalty, as predicted.

The findings of this study, however, should be interpreted with the following limitations in mind. Since the proposed model of this study is tested on Chinese customers, the generalizability of the findings could be limited to the Chinese socio-cultural contexts. However, some sub-cultures in Western society may share similar relational dynamics as the Chinese collectivistic culture (e.g., the Mormon culture in Utah and new immigrants, such as Vietnamese in California or Cubans in Florida), thus increasing the relevancy of the findings to such sub-cultural groups, but the actual application of the findings to non-Chinese cultural contexts will require additional research. Therefore, cross-cultural or sub-cultural comparative studies, as well as replication research in different services contexts, should be conducted in the future to provide a useful empirical platform to enhance the external validity of the findings.

\section{AUTHOR INFORMATION}

Prem Shamdasani: Associate Professor, Department of Marketing, NUS Business School, National University of Singapore, Mochtar Riady Building, 15 Kent Ridge Drive, \#08-060, Singapore 119245. E-mail: bizps@ nus.edu.sg. Tel: +65-6516-6264. Fax: +65-6779-5941. He received his PhD in Marketing in 1990 from the University of Southern California and has published in the Journal of Consumer Research, Journal of Advertising Research, European Journal of Marketing, Asian Journal of Marketing, Journal of Retailing and Consumer Services and the Services Industries Journal.

Kwon Jung: Professor, KDI School of Public Policy and Management, P.O. Box 184 Cheongnyang, Seoul 130650, Korea. E-mail: jungk@ kdischool.ac.kr. Tel: +822-3299-1036. Fax: +822 3299-1240. (Contact person). Kwon Jung is a professor at KDI School of Public Policy \& Management. He has a PhD in marketing and has published several research papers in journals such as Journal of International Business Studies, Journal of International Marketing, Psychology and Marketing and others. His research interests include areas of branding, cross-cultural consumer behaviors and Internet consumer behaviors.

\section{REFERENCES}

1. Andreson, C. and M. Martin (1995),The Effects of Communicatuion Motives, Interation Involvement and communication Loneliness on Satisfaction, Small Group Research, 26(1), 118-137.

2. Anderson, E. and B. Weitz (1989), Determinants of Continuity in Conventional Industrial Channel Dyads, Marketing Science, 8(4), 310-323. 
3. Anderson, E. and M.W. Sullivan (1993), The Antecedents and Consequences of Customer Satisfaction for Firms, Marketing Science, 12(Spring), 125-143.

4. Anderson, J.C. and D.W. Gerbing (1988), Structural Equation Modeling in Practice: A Review and Recommended Two-Step Approach, Psychological Bulletin 103(3), 411-423.

5. Anderson, K.E. (1972), Introduction to Communication Theory and Practice, Menlo Park, CA: Cummings Publishing Co.

6. Archer, R.L. (1979), Anatomical and Psychological Sex Differences, in G.J. Chelune and Associates (eds.), Self-disclosure: Origins, Patterns, and Implications of Openness in Interpersonal Relationships, San Francisco, CA: Jossey-Bass, 80-109.

7. Athanasopoulou, Pinelopi (2009), Commentary: Relationsjip Quality: A Critical Literature Review and Research Agenda, European Journal of Marketing, 43 (5/6), 583-610.

8. Bagozzi, Richard P. and Youjae Yi (1988), On the Evaluation of Structural Equation Models, Journal of the Academy of Marketing Science, 16, 74-94.

9. Bagozzi, Richard P., Youjae Yi, and Lynn W. Phillips (1991), Assessing Construct Validity in Organizational Research, Administrative Science Quarterly, 33 (3), 421-458.

10. Bass, B.M. (1960), Leadership, Psychology, and Organizational Behavior, New York: Harper Brothers.

11. Berry, L.L. (1983), Relationship Marketing. Emerging Perspectives in Marketing, Proceedings of the AMA Conference, 25-28.

12. Berry, L.L. (1995), Relationship Marketing of Services-Growing Interest, Emerging Perspectives, Journal of the Academy of Marketing Science, 23(Fall), 236-245.

13. Boorom, M.L., J.R. Goolsby and R.P. Ramsey (1998), Relational Communication Traits and Their Effect on Adaptiveness and Sales Performance, Journal of the Academy of Marketing Science, 26(1), 16-30.

14. Bryne, D. (1971), The Attraction Paradigm, New York: Academic Press.

15. Castleberry, S.B. and C.D. Shepherd (1993), Effective Interpersonal Listening and Personal Selling, Journal of Personal Selling \& Sales Management, 13(Winter), 35-49.

16. Chen, Zhen Xiong, Yizheng Shi, and Da-Hai Dong (2008), An Empirical Study of Relationship Quality in a Service Setting: A Chinese Case, Marketing Intelligence \& Planning, 26 (1), 11-25.

17. Collins, N.L. and L.C. Miller (1994), The Disclosure-Liking Link: From Meta-analysis Toward a Dynamic Reconceptualization, Psychological Bulletin, 116, 457-475.

18. Comer, J.M. (1984), A Psychometric Assessment of a Measure of Sales Representatives' Power Perceptions, Journal of Marketing Research, 21(May), 221-225.

19. Crosby, L.A, K.R. Evans, and D. Cowles (1990), Relationship Quality in Services Selling: An Interpersonal Influence Perspective, Journal of Marketing, 54(July), 68-81.

20. Day, G.S. (2000), Managing Market Relationships, Journal of the Academy of Marketing Science, 28, 2430.

21. Dick, A. and Basu, K. (1994). Customer Loyalty: Toward an Integrant Conceptual Framework, Journal of the Academy of Marketing Science, 22(2), 99-113.

22. Doney, P.M. and J.P. Cannon (1997), An Examination of the Nature of Trust in Buyer-Seller Relationships, Journal of Marketing, 61(April), 35-51.

23. Duncan, T. and S. E. Moriarty (1998), A Communication-Based Marketing Model for Managing Relationships, Journal of Marketing, 62(April), 1-13.

24. Farh, J. L., A.S. Tsui, K. Xin, and B. S. Cheng (1998), The Influence of Relational Demography And Guanxi: The Chinese Case, Organization Science, 9(4), 471-488.

25. Fornell, C. (1992), A National Customer Satisfaction Barometer: The Swedish Experience, Journal of Marketing, 56(January), 6-21.

26. Fornell, C. and D. F. Larcker (1981), Evaluation Structural Equation Models with Unobservable Variables and Measurement Error, Journal of Marketing Research, 28, 39-50.

27. Friman, M., T. Gärling, B. Millet, J. Mattssin, R. Johnston (2002), An Analysis of International Businessto-Business Relationships Based on the Commiment-Trust Theory, Industrial Marketing Management, 31, 403-409.

28. Gao, G. (1996), Self and Other: A Chinese Perspective on Interpersonal Relationships, in William B. Gudykunst, Stella Ting-Toomey, and Tsukasa Nishida (eds.), Communication in Personal Relationship Across Cultures, Sage Publications, 8-101.

29. Gerbing, D. W and J. C. Anderson (1988), An Updated Paradigm for Scale Development Incorporating 
Unidimensionality and Its Assessment, Journal of Marketing Research, 25, 186-192.

30. Gordon, M.E., K. McKeage, and M.A. Fox (1998), Relationship Marketing Effectiveness: The role Of Involvement, Psychology and Marketing, 15(5), 443-459.

31. Gronroos, C. (1990). Relationship Approach to the Marketing Function in Service Contexts: The Marketing and Organizational Behavior Interface, Journal of Business Research, 20(1), 3-12.

32. Gümmerson, E. (1987), The New Marketing: Developing Long-Term Interactive Relationships, Long Range Planning, 20 (4), 10-20.

33. Hennig-Thurau, T. and A. Klee (1997), The Impact of Customer Satisfaction and Relationship Quality on Customer Retention: A Critical Reassessment and Model Development, Psychology and Marketing, 14(8), 737-763.

34. Hennig-Thurau, T., K.P. Gwinner, and D.D. Gremler (2002), Understanding Relationship Marketing Outcomes: An Integration of Relational Benefits and Relational Quality, Journal of Service Research, 4, 230-247.

35. Hofsted, G. (1980), Culture's Consequences: International Differences in Work-related Values, Beverly Hills, CA: Sage.

36. Hogg, M.A. and D. Abrams (1990), Social Motivation, Self-esteem and Social Identify, in D. Abrams and M. Hogg (eds.), Social Identify Theory: Constructive and Critical Advances, New York: Harvester Wheatsheaf, 28-47.

37. Kotler, P. and G. Amstrong (2010), Principles of Marketing, 13th Edition, Upper Saddle River, NJ: Prentice Hall.

38. Kramer, R. M. (1991), Intergroup Relations and Organizational Dilemmas: The Role of Categorization Processes, in B. M. Stawand, L.L. Cummings (eds.), Research in Organizational Behavior 13, Greenwich, CT: JAT Press, 191-228.

39. Kurtz, D.L. and K.E. Clow (1998), Services Marketing, New York: John Wiley \& Sons.

40. Lincoln, J. R. and J. Miller (1979), Work and Friendship Ties in Organizations: A Comparative Analysis of Relational Networks, Administrative Science Quarterly, 24, 181-199.

41. $\quad$ Lynch, J.J. (1995), Customer Loyalty and Success, London: MacMillan Press Ltd.

42. Mittal, B. and W.M. Lassar (1996), Personalization in Service Encounters, Journal of Retailing, 72(1), 95109.

43. Moorman, Christine R., Gerald Zaltman, and Rohit Deshpande (1992), Relationships Between Providers and Users of Market Research: The Dynamics of Trust Within and Between Organizations, Journal of Marketing Research, 26 (August), 31, 314-32

44. Morgan, R.M. and S. D. Hunt (1994), The Commitment-Trust Theory of Relationship Marketing, Journal of Marketing, 58(July), 20-38.

45. Nunnally, J. C. and I. H. Berstein (1994), Psychometric Theory, New York: McGraw Hill.

46. Palmatier, R. W., Rajiv P. Dant, Dhruv Grewal, and Kenneth R. Evans (2006), Factors Influencing the Effectiveness of Relationship Marketing: A Meta-Analysis, Journal of Marketing, 70 (October), 136-153.

47. Parasuraman, A., V.A. Zeithaml, and L.L. Berry (1985), A Conceptual Model Service Quality and Its Implications for Future Research, Journal of Marketing, 49(Fall), 41-50.

48. Perrien, J.and L. Ricard (1995), The Meaning of A Marketing Relationship: A Pilot Study, Industrial Marketing Management, 24, 37-43.

49. Ramsey, R.P. and R.S. Sohi (1997), Listening to Your Customers: The Impact of Perceives Salesperson Listening Behavior on Relationship Outcomes, Journal of the Academy of Marketing Science, 25(2), 127 137.

50. Ryan, M.J., T. Buzas, and V. Ramaswamy (1995), Making CSM A Power Tool, Marketing Research, 7(3), 11-16.

51. Sanzo, M. S., M. L. Santos, R. Vasquez, and L. I. Alvarez (2003), The Effect of Market Orientation on Buyer-Seller Relationship Satisfaction, Industrial Marketing Management, 32 (4), 327-345.

52. Schutz, W. C. (1966), The Interpersonal Underworld, 2nd Edition, Palo Alto, CA: Science and Behavior Books.

53. Selnes, F. (1998), Antecedents and Consequences of Trust and Satisfaction in Buyer-Seller Relationships," European Journal of Marketing, 32 (3/4), 305-322.

54. Smith, J.B. (1998), Buyer-Seller Relationships: Similarity, Relationship Management, and Quality, Psychology and Marketing, 15(1), 3-21. 
55. Steil, L.K., L.L. Barker, and K.W. Watson (1983), Effective Listening: Key to Your Success, New York: McGraw-Hill.

56. Suprenant, C.F. and M.R. Solomon (1987), Predictability and Personalization in the Service Encounter, Journal of Marketing, 51(April), 73-80.

57. Tajfel, H. and J. C. Turner (1976), An Integrative Theory of Intergroup Conflict, in W. G. Austin and S. Worchel (Eds.), The Social Psychology of Intergroup Relations, Monterey, CA: Brooks/Cole, 33-48.

58. Triandis, H. (1988), Collectivism vs. Individualism: A Reconceptualization of a Basic Concept in CrossCultural Psychology, in C. Bagley \& G. Verma (eds.), Cross-Cultural Studies of Personality, Attitudes, and Cognition, London: Macmillian, 60-95.

59. Tsui, A. and C. O'Reilly (1989), Beyond Simple Demographic Effects: The Importance Of Relational Demography in Superior-Subordinate Dyads, Academy of Management Journal, 32, 402-423.

60. Vieira, Armando Luis, Heidi Winklhofer, and Christine T. Ennew (2008), Relationship Quality: A Literature Review and Research Agenda, Journal of consumer Behavior, 7 (4), 269-291.

61. Webster, F.E, Jr, (1968), Interpersonal Communication and Salesman Effectiveness, Journal of Marketing, 32(July), 7-13.

62. Williams, K.C. and R.L. Spiro (1985), Communication Style in the Salesperson-Customer Dyad, Journal of Marketing Research, 22(November), 432-442.

63. Williams, K.C. and R.L. Spiro, and L.M. Fine (1990), The Customer-Salesperson Dyad: An Interaction/Communication Model and Review, Journal of Personal Selling and Sales Management, 10(Summer), 29-43.

64. Wilson, D.T. (1995), An Integrated Model of Buyer-Seller Relationships, Journal of the Academy of Marketing Science, 23(4), 335-345.

65. Wong, A. and A. Sohal (2002) An Examination of the Relationship between Trust, Commitment and Relationship Quality, International Journal of Retail \& Distribution Management, 30, 34-50.

66. Wray, B., A. Palmer, and D. Bejou (1994), Using Neural Network Analysis to Valuate Buyer-Seller Relationship, European Journal of Marketing, 28, 32-48.

67. Yau, O., J. Lee, R. Chow, L. Sin, and A. Tse (2000), Relationship Marketing the Chinese Way, Business Horizons, 43 (1), 16-24.

68. Zeithaml, V.A., L.L. Berry, and A. Parasuraman (1996), The Behavioral Consequences of Service Quality, Journal of Marketing, 60(April), 31-46.

69. Zeithaml, V.A. and M.J. Bitner, and D. Gremler (2008), Services Marketing, $5^{\text {th }}$ edition, New York: McGraw Hill. 
International Business \& Economics Research Journal - June 2011

Volume 10, Number 6

\section{NOTES}

